\title{
Rotavirus vaccine in India faces controversy
}

A new pediatric vaccine for rotavirus that apparently showed $56 \%$ efficacy in a phase III clinical trial has run into controversy, according to an expert who points to the need for more safety data and questions the rationale for including it in routine immunization.

The vaccine, ROTAVAC, was developed by Bharat Biotech in collaboration with the Government of India's Department of Biotechnology. It is being considered for licensing by the Drugs Controller General of India and for inclusion in the national immunization program.

Provisionally priced at US\$1 per dose, the vaccine is much less expensive than RotaTeq and Rotarix, each of which costs more than US $\$ 15$ per dose in India. The efficacy of these vaccines varies, depending on the strain of the virus and other factors, from a high of 80\%-96\% in the United States, Hong Kong, Taiwan and Singapore, to a low of $77 \%$ in South Africa and 50\% in Malawi (www.who.int/immunization /sage/3_Detailed_Review_Paper_on _Rota_Vaccines_17_3_2009.pdf).

ROTAVAC, an oral vaccine, would be administered to infants in a threedose course at the ages of 6,10 and 14 weeks. According to the Indian government's media release, ROTAVAC reduces severe diarrhea by $56 \%$ during the first year of life, with protection continuing into the second year of life.

The Indian government describes it as "an important scientific breakthrough." Rotavirus is the most severe and lethal cause of childhood diarrhea in India, accounting for $22 \%$ of all diarrhea-related deaths in the under-five population, or 98621 deaths annually.

"The clinical results indicate that the vaccine, if licensed, could save the lives of thousands of children each year in India," stated Dr. K. VijayRaghavan, secretary of the Department of Biotechnology, in a news release (http://pib.nic .in/newsite/erelease. aspx ?relid=95976).

Diarrhea-related diseases account for more than 1 in 10 under-five deaths, or

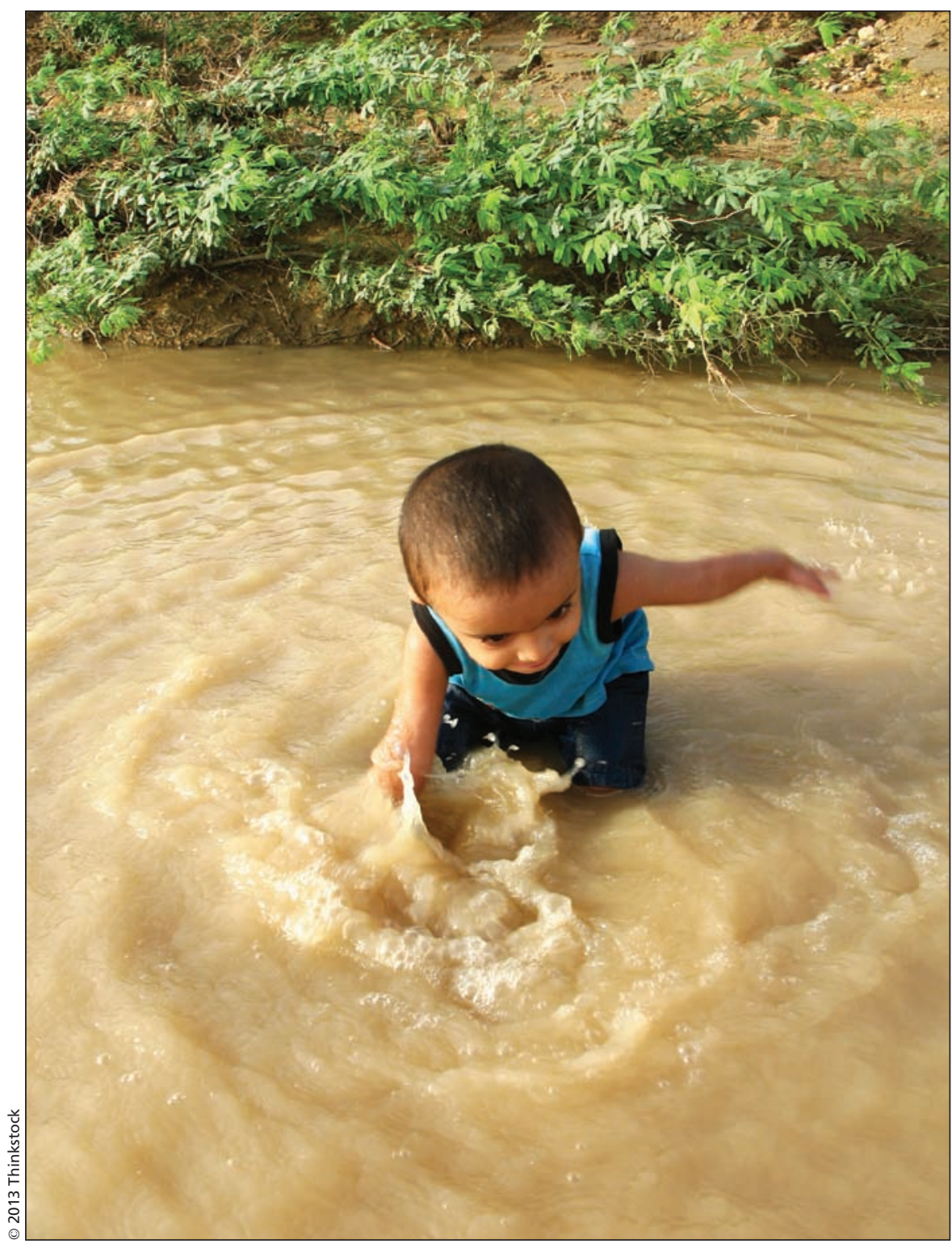

Rotavirus, which can be transmitted through fecally contaminated water, is the most severe and lethal cause of childhood diarrhea in India, accounting for $\mathbf{2 2} \%$ of all diarrhearelated deaths in the under-five population, or 98621 annually.

about 800000 annually, according to the World Health Organization (WHO) and UNICEF (www.who.int/maternal _child_adolescent/documents/97892415 98415/en/). Rotavirus is the most common pathogen, accounting for $37 \%$ of all diarrhea-related deaths and $5 \%$ of all deaths in under-five children globally.

Chandrakant Lahariya, an immunization specialist at WHO in New Delhi, said that although $56 \%$ efficacy may not seem good, " in a disease like rotavirusrelated diarrhea with a huge burden it will indeed have a huge impact in terms of the number of lives saved. ... Interventions in all ways should be tried to save the maximum number of lives. The price of the vaccine at just about US\$1 is also not so huge."

However, another expert is more 
skeptical. "Do you know another vaccine with $50 \%$ efficacy that is used for public health programs?" asks Jacob Puliyel, head of the Department of Pediatrics, St. Stephen's Hospital, Tis Hazari, Delhi. "It is a toss-up if the vaccine will work for you. If $100 \%$ [of the] population is vaccinated it will reduce $50 \%$ [of the] rotavirus deaths. What are the numbers needed to treat [to prevent one death]?" he asks.

The answer to his questions will only be available once the study results are published in a peer-reviewed journal, but that hasn't happened yet, prompting another criticism from Puliyel. "I think the fact that this [vaccine] was announced before peer review, [means] it will never be properly reviewed. That is the story that must come out," Puliyel told CMAJ.

In fact, the government announce- ment came before the study was even officially completed. According to the clinical trials registry, the estimated study completion date is April 2014, with an estimated primary completion date of December 2013, both months away.

There are also questions about the new vaccine's safety. According to Puliyel, the incidence of intusussception is 1 in 50000 among infants vaccinated with Rotarix, the new GlaxoSmithKline Inc. vaccine, which was studied in 70000 participants. By contrast, the ROTAVAC vaccine trial enrolled only 6800 participants, which is a small number to establish safety for rare events (http://clinicaltrials.gov /show/NCT01305109).

"They have to publish urgently about safety," said Puliyel.

The US Centers for Disease Control and Prevention estimates that 1-3 infants out of 100000 might develop intussuception within seven days of getting the first dose of the RotaTeq or Rotarix vaccine .

MK Bhan, former secretary in the Department of Biotechnology, stated in the government announcement that the "vaccine efficacy compares favourably with the efficacy of the currently licensed rotavirus vaccines in low-resource countries."

However, no one is commenting on the fact that according to data in the clinical trials registry, the safety and efficacy of the new ROTAVAC vaccine was only compared to placebo, not to any "currently licensed rotavirus vaccine" as Bhan claims. http://clinicaltrials.gov /show/NCT01305109). — Soumyadeep Bhaumik MBBS, Kolkata, India

CMAJ 2013. DOI:10.1503/cmaj.109-4543 